\title{
Oral Health Impact Profile
}

National Cancer Institute

\section{Source}

National Cancer Institute. Oral Health Impact Profile. NCI Thesaurus. Code C62359.

Measures a person's perceptions of the social impact of oral disorders on their wellbeing; measures self-reported dysfunction, discomfort and disability attributed to oral conditions. 